\title{
Role of Nanomedicine in Management and Prevention of COVID-19
}

\author{
Jitendra N. Wankar ${ }^{1 \dagger}$, Vivek K. Chaturvedi ${ }^{2}$, Chandrashekhar Bohara ${ }^{3}$, Mohan P. Singh ${ }^{2}$ \\ and Raghvendra A. Bohara ${ }^{4 * t \neq}$ \\ ${ }^{1}$ The Council for Scientific and Industrial Research, Centre for Cellular and Molecular Biology-Annexe-Il, Medical \\ Biotechnology Complex, Hyderabad, India, ${ }^{2}$ Centre of Biotechnology, University of Allahabad, Prayagraj, India, ${ }^{3}$ Kurana \\ Trust, Bengaluru, India, ${ }^{4}$ Centre for Interdisciplinary Research, D. Y. Patil Education Society, Kolhapur, India
}

OPEN ACCESS

Edited by:

Ajeet Kaushik,

Florida Polytechnic University,

United States

Reviewed by:

Vinoth Kumar Lakshmanan, Sri Ramachandra Institute of Higher Education and Research, India Suresh K. Verma, KIIT University, India

*Correspondence:

Raghvendra A. Bohara

raghvendrabohara@gmail.com

tThese authors have contributed equally to this work and share first authorship

¥Present address:

Raghvendra A. Bohara, CÚRAM, SFI Research Centre for Medical Devices, National University of Ireland, Galway, Ireland

Specialty section: This article was submitted to Biomedical Nanotechnology, a section of the journa

Frontiers in Nanotechnology

Received: 30 July 2020 Accepted: 28 September 2020 Published: 16 December 2020

Citation: Wankar JN, Chaturvedi VK, Bohara C, Singh MP and Bohara RA (2020) Role of Nanomedicine in Management and Prevention of COVID-19.

Front. Nanotechnol. 2:589541.

doi: 10.3389/fnano.2020.589541
COVID-19, or the Coronavirus disease 2019, caused by the severe acute respiratory syndrome coronavirus 2 (SARS-CoV-2) has become a pandemic. At the time of writing this (July 28, 2020), more than 17 million people have become affected and 0.7 million people have died across the world. Remdesivir has shown glimpses of insight into how to fight the virus, but as of yet remain far from victory. Nanotechnology has proven its role in medicine to deliver the drug at the target site with minimal side effects, particularly in the anticancer domain. Most specifically, a range of nanotechnology-based products, such as nanosilver, are currently on the market because they have demonstrated the potential to combat viruses. This article provides an overview of the role of nanomedicine, including polymeric and inorganic materials, and its future capabilities in the management of the disease outbreak. Taking all this into account, an attempt has been made to educate readers in the simplest way of the role of nanomedicine, which can play a pivotal role in the management of diseases.

Keywords: COVID-19, pulmonary drug delivery, nanomedcine, nanotherapeutics, gold nano-particles

\section{INTRODUCTION}

The disastrous outbreak of COVID-19 originated in China, and its Wuhan province was the first epicenter of this pandemic (Wu et al., 2020). As of now, 17 million people worldwide have been infected and over 0.7 million people have lost their lives and still, this number is continuing to rise with many people losing their lives each day. This is one of the biggest catastrophes in human history since world war II, in which the whole world is affected by this frightening situation. The recent outbreak of COVID-19 has created a global emergency for the management of the crisis. COVID-19 is a severe acute respiratory syndrome coronavirus 2 (SARS-CoV-2) caused by a novel coronavirus that has encountered humans for first time, and as a result humans lack the innate immunity to fight against this novel strain of the coronavirus which results in severe miscommunication among health care facilities (Al-Qahtani, 2020; Wu et al., 2020). Due to the pandemic situation, it was difficult to handle the enormous amounts of patients who required treatment, which placed a burden on the healthcare industry, and the death rate was higher than expected. The majority of the world experienced a complete lockdown situation to combat the outbreaks and limit the spreads of the virus (Liu et al., 2020). The term "Corona" is the Latin name for "crown" and has been assigned to the coronavirus due to its structure seen under electron transmission microscopy. It is a typical RNA virus family (Figure 1) that is divided into four 
categories- $\alpha, \beta, \gamma$, and $\delta$ which has a single-stranded RNA as a genetic material with capsid of the virus enclosed with a virus genome and club-shaped protein spikes on the surface. The $\beta$ class of the coronavirus was known prior to this current pandemic, and it is the same class accountable for the previous outbreak, severe acute respiratory syndrome (SARS) and the Middle East respiratory syndrome (MERS) (Al-Qahtani, 2020) SARS-CoV-2 is highly contagious and said to be spread with contact with an infected person, surfaces, and air droplets via the mouth, nose, and eye. It has a long incubation period of around 14 days and shows initial symptoms similar to typical seasonal virus infection like fever, dry cough, and fatigue with difficulty in breathing. However, as the infection spreads in the body, it can cause severe pneumonia with inflammation and fibrosis in the lungs and result in respiratory failure due to inefficient gas exchanges that lead to multiple vital organ (heart, kidney, liver, GIT, and brain) failure and a person can die if artificial oxygen is not provided on time (Al-Qahtani, 2020; Chauhan et al., 2020).

Nanotechnology could play a potential role in multidisciplinary areas like as health, defense, agriculture, and many more. Currently in the available literature, nanotechnology will play a vital role in bringing multi-disciplinary ways of developing affordable, reliable, and powerful tools for the diagnosis and therapeutics of different serious diseases. Various metallic and non-metallic nanoparticles (NPs) like magnetic nanoparticles (Bohara et al., 2017), Zinc Oxide nanoparticles (Verma et al., 2017a,c; Das et al., 2019) (ZnONPs), Cuprous Oxide nanoparticles (Kumari et al., 2017) (CuONPs), Silver nanoparticles (Verma et al., 2017b, 2018b; Paul et al., 2018) (AgNPs), Nanosized Copper (I) Iodide particles (Kumari et al., 2018) (CuINPs), Gold nanoparticles on Silica nanoparticles (Verma et al., 2018a) (Au-SiO2NPs) and some other organic nanoparticles (Arun et al., 2019) are very promising to inactivate the COVID19 infection. This perspective review explains the current progression of nanotechnology for the detection and treatment of viral infections with a focus on coronaviruses especially regarding SARS-CoV-2.

\section{THE POTENTIAL ROLE OF NANOMEDICINE IN COVID-19}

The sudden outbreak has created an urgent need for medicine to tackle the virus. To date, there is no standard therapy for the treatment and doctors have tried many methods to manage the symptoms with existing drug molecules such as Chloroquine, Hydroxychloroquine, Ribavirin, Favipiravir, Galidesivir, thalidomide, Emtricitabine, Tenofovir, Baricitinib, Remdesivir, Ruxolitinib, Darunavir, Camostat, Fingolimod, Umifenovir, Lopinavir, and Ritonavir. These drug molecules often suffer from poor solubility, permeability, and lack of targetability that leads to failure in exerting the desired therapeutic effect (Chauhan et al., 2020; Shah et al., 2020) Nanotechnology has proven its role in medicine to deliver the drug at the target site with minimal side effects. Several nanotechnology-based products are currently on the market and are under clinical investigation.

Most common problems with drug molecules for COVID 19 like infection

1. BCS class II (high permeability and low solubility), III (High solubility and low permeability), IV (low solubility and low permeability)

2. Non-specific drug distribution and high dose-related toxicity

3. The short plasma half-life of the drug molecules.

Nanomedicine has many facets that can be precisely utilized to deliver the drug molecules to infected cells, and the targeted ligand conjugated nanoparticle specifically binds with epitopes of the virus that results in inactivation of the virus, causing it to fail to enter the cells. Thus, the infection can be neutralized with nanomedicine-based approaches as shown in Figure 1.

Several nanocarriers have been exploited for drug delivery to solve the problem associated with drug molecules. These can be divided into two categories, polymeric and inorganic nanocarriers.

In many research labs around the world, scientists are working on nanoparticle-based vaccine products which are still in consideration such as Novavax developing a protein subunit of a nanoparticle vaccine + matrix $M$ (adjuvant) (based on recombinant SARS-CoV-2 glycoprotein). The University of Tokyo/ Daiichi-Sankyo is working on the $\mathrm{RNa}$ based lipid nanoparticles (LNP)-encapsulated mRNA for the SARS-CoV-2 infection-causing viruses. Similarly, The Scientific Research Institute of Vaccines and Sera, Saint Petersburg is working on a nanoparticle vaccine (recombinant protein) (S protein and other epitopes based) (Verma et al., 2017a,c; Das et al., 2019; Khalaj-Hedayati et al., 2020).

\section{INORGANIC AND POLYMER-BASED NANOCARRIERS FOR COVID 19 TREATMENT}

A polymer of natural or synthetic origin can form highly complex structures with varying parameters during synthesis. The size, composition and shape can be tailorable, which has a significant impact on the morphology and behavior of the polymeric nanocarrier. Natural, synthetic, and semisynthetic materials can be used to fabricate the nanocarrier such as polymeric nanoparticles, liposome, cyclodextrin complexes etc.

\section{POLYMERIC SOLID COLLOIDAL NANOPARTICLES}

Polymeric nanoparticles enable the safe in-vivo administration of the drug molecules with its unique properties such as improved safety and efficacy, controlled drug release and targeted drug 


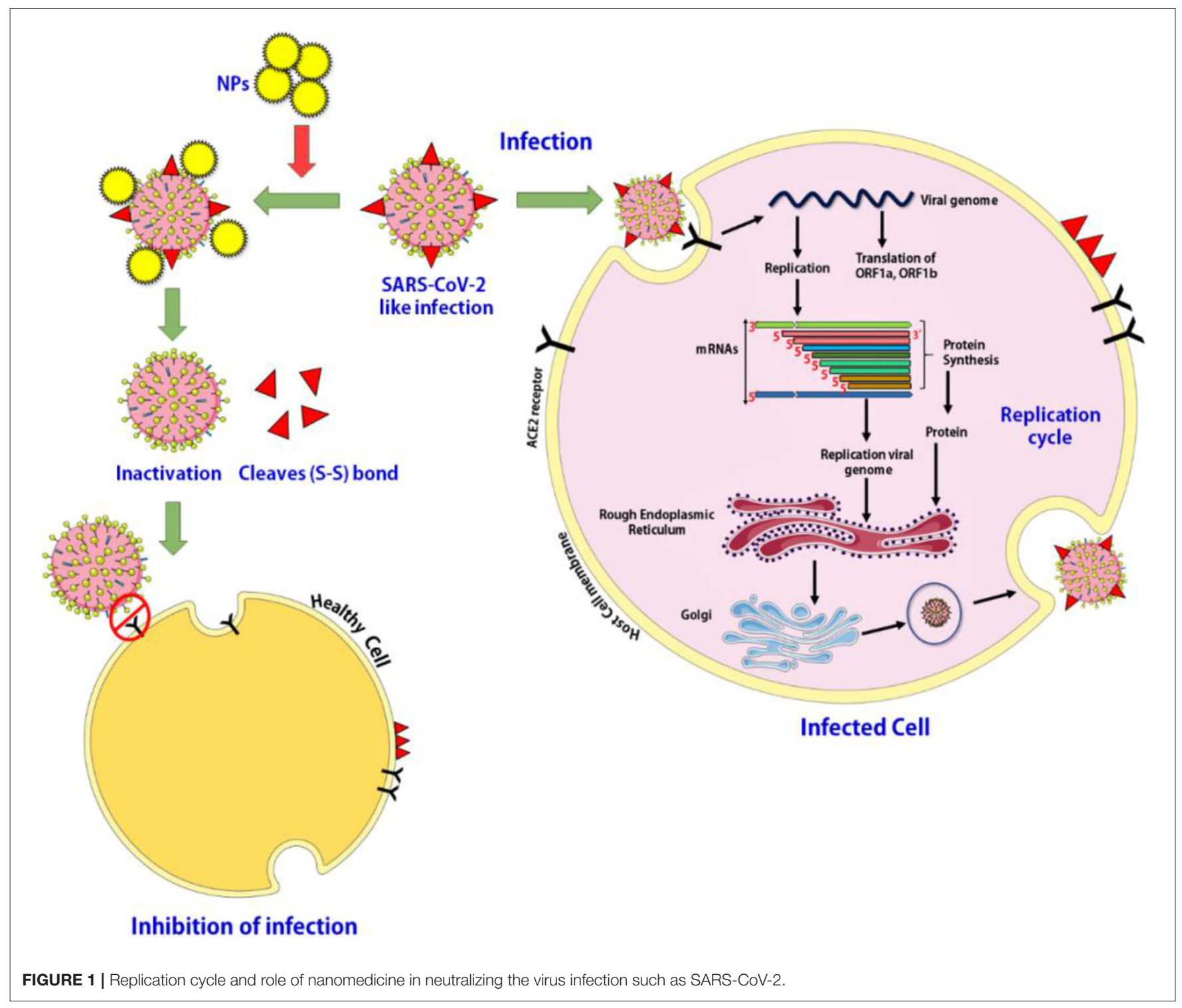

delivery (Kumari et al., 2017; Verma et al., 2017b, 2018b; Paul et al., 2018). It also reduces the high dose-related side effects and permeability across the cellular membrane due to its nano-size properties. This beneficial effect of the polymeric nanoparticle can be utilized for drug delivery to revive the existing drug to treat the SARS-CoV-2 infection. Zhang et al. (2020), have developed the poly (lactic-co-glycolic acid) (PLGA) polymerbased nanosponge to tackle SARS-CoV-2 Infectivity. Mainly, human lung epithelial type II cells and human macrophages membrane-coated nanosponge was fabricated with PLGA as the inner core material which shares the same cellular physiology required for the entry of SARS-CoV-2 into host cells. This artificial cellular nanosponge acts as a receiving target for SARSCoV-2 during incubation where it becomes neutralized and unable to infect the host cells (Kumari et al., 2018). In this way, the polymeric nanoparticle is a potential nanocarrier system to deliver drugs to treat SARS-CoV-2 infection.

\section{LIPOSOMAL TARGETED DELIVERY TO TREAT COVID-19 DISEASE}

The liposome is a lipid bilayer vesicle and has been widely utilized for the delivery of hydrophobic and hydrophilic drugs. The liposome can functionalize as a "stealth liposome" that shows long systemic circulation, targeted and stimulus-responsive drug delivery. Due to its biocompatible and biodegradable nature, it is one of the preferred carriers for drug formulation and can be a potential platform for developing the novel formulation to treat COVID-19 infection. Ohno et al. (2009), have studied the synthetic peptides-based liposomes to treat SARS coronavirus infection. The chemically conjugated peptideliposome is effective for the induction of cytotoxic T lymphocytes that clears the virus load and can be a potential treatment strategy against SERS (Verma et al., 2018a). Tai et al. (2020), Investigated the liposome-based novel formulation of hydroxychloroquine 
in Sprague-Dawley (SD) rats as a potential treatment for COVID-19. This inhalable formulation has found a higher drug concentration in the lungs $(\sim 30$-fold $)$ with a longer half-life in lung and lower exposure to another organ such as the heart compared to intravenous injection (Arun et al., 2019). Thus, the liposome as a carrier system may impart distinctive advantages for drug delivery to treat the COVID19 infection.

\section{CYCLODEXTRIN COMPLEXES PREVENT INFECTION AND PROGRESSION OF COVID-19}

Cyclodextrin is a natural cyclic polysaccharide containing $\alpha$, $\beta$, and $\gamma$ as a basic unit. It has been widely explored as a pharmaceutical solubilizer to developed formulation via hostguest complexation to dissolve the hydrophobic and hydrophilic drug molecules (Shah et al., 2020). Currently, cyclodextrin nanoparticles have gained attention due to the presence of multiple units of cyclodextrin that dissolved a higher quantity of drug compared to native cyclodextrin (Khalaj-Hedayati et al., 2020). It is one of the generally recognized as safe (GRAS) materials for human administration and has been proved safe for many decades and has many established formulations on the market. Recently, the FDA has approved the cyclodextrin-based formulation of Remdesivir for the treatment of COVID-19 (Jones et al., 2020), and it has shown promising effects in a clinical scenario against several other viruses such as Nipah virus ( $\mathrm{Li}$ C. et al., 2020) and MERS-CoV infection (de Wit et al., 2020; Sheahan et al., 2020). Cyclodextrin not only acts a pharmaceutical solubilizer for the mainly hydrophobic drug but it also has antiinfective properties against several viruses (Kumari et al., 2017; Jones et al., 2020) Hence, cyclodextrin may be considered as a potential delivery vehicle for the pulmonary aerosol for localized drug delivery to the lungs.

\section{INORGANIC AND METALLIC BASED NANOCARRIER FOR COVID 19 TREATMENT}

Various metal nanoparticles such as gold, silver, platinum, gadolinium, silica, and its hybrid nanostructure can be used to synthesize inorganic nanocarrier for drug delivery (Jadhav et al., 2018; Chaturvedi et al., 2020). The silver nanoparticle is known for its broad-spectrum antimicrobial activity and is an active component in pharmaceutical products such as silver-sulfasalazine where silver ion enhances the antimicrobial property of sulfasalazine drug. It has been used in the treatment

TABLE 1 | Inorganic nanocarriers' roles in the treatment of viruses like SARS-CoV-2.

\begin{tabular}{|c|c|c|c|c|c|c|}
\hline S.No. & $\begin{array}{l}\text { Name of } \\
\text { Nanomaterials }\end{array}$ & Strategies used & $\begin{array}{l}\text { COVID like respiratory } \\
\text { viruses }\end{array}$ & $\begin{array}{l}\text { Animal model } \\
\text { (Host) }\end{array}$ & Dose & References \\
\hline 1 & $\mathrm{Ag}_{2} \mathrm{~S}$ nanoclusters & $\begin{array}{l}\text { Inhibition of viral } \\
\text { proliferation } \\
\text { in vitro cells }\end{array}$ & $\begin{array}{l}\text { Porcine epidemic diarrhea virus } \\
\text { (PEDV) }\end{array}$ & Pig & $46 \mu \mathrm{g} / \mathrm{ml}$ & (Du et al., 2018) \\
\hline 2 & $\begin{array}{l}\text { Bio polymeric } \\
\text { nano/microspheres } \\
\text { N-(2-hydroxypropyl)- } \\
\text { 3-trimethyl } \\
\text { chitosan- } \\
\text { nano/microsphere } \\
\text { (HTCC-NS/MS) }\end{array}$ & $\begin{array}{l}\text { Capable of } \\
\text { adsorbing } \\
\text { coronaviruses }\end{array}$ & $\begin{array}{l}\text { Human coronavirus NL63 } \\
\text { (HCoV-NL63) }\end{array}$ & Human & $10 \mathrm{mg} / 500 \mu \mathrm{l}$ & (Ciejka et al., 2017) \\
\hline 3 & $\begin{array}{l}\text { GO-Ag } \\
\text { nanocomposite }\end{array}$ & $\begin{array}{l}\text { Antiviral activity } \\
\text { against enveloped } \\
\text { viruses }\end{array}$ & Feline coronavirus (FCoV) & Cat & $0.1 \mathrm{mg} / \mathrm{ml}$ & (Chen et al., 2016) \\
\hline 4 & Diphyllin nanoparticles & $\begin{array}{l}\text { Inhibition of } \\
\text { endosomal } \\
\text { acidification } \\
\text { responsible for virus } \\
\text { uncoating and } \\
\text { cytoplasmic entry }\end{array}$ & $\begin{array}{l}\text { Feline Infectious Peritonitis } \\
\text { Virus (FIPV) }\end{array}$ & Cat & $2 \mu \mathrm{M}$ & (Hu et al., 2017) \\
\hline 5 & Ag NPs, Ag NW & $\begin{array}{l}\text { Inhibition of cell } \\
\text { apoptosis induced } \\
\text { by the virus }\end{array}$ & $\begin{array}{l}\text { Transmissible gastroenteritis } \\
\text { virus (TGEV) }\end{array}$ & Pig & $3.125-12.5 \mu \mathrm{g} / \mathrm{ml}$ & (Lv et al., 2014) \\
\hline 6 & $\begin{array}{l}\text { Composites with silver } \\
\text { colloid and titanium } \\
\text { dioxide nanoparticles }\end{array}$ & $\begin{array}{l}\text { Inhibited the growth } \\
\text { of the viruses }\end{array}$ & $\begin{array}{l}\text { Transmissible gastroenteritis } \\
\text { virus (TGEV) and porcine } \\
\text { epidemic diarrhea virus (PEDV) }\end{array}$ & Pig & 1,000-fold diluted from original & (Cho et al., 2014) \\
\hline 8 & $\begin{array}{l}\text { PLGA nanoparticles } \\
\text { (PLGA-KAg) }\end{array}$ & $\begin{array}{l}\text { Induced } \\
\text { cross-protective } \\
\text { cell-mediated } \\
\text { immune response }\end{array}$ & $\begin{array}{l}\text { Bovine parainfluenza } 3 \text { virus } \\
\text { (BPI3V) Swine influenza virus } \\
(\mathrm{H} 1 \mathrm{~N} 2)\end{array}$ & Pig & $2 \mu \mathrm{g} / \mathrm{ml}$ & (Dhakal et al., 2017) \\
\hline
\end{tabular}


of wound dressing and burn care products. Moreover, silver has recorded anti-cancer, anti-inflammatory, antiplatelet, antiangiogenesis antifungal, and antibacterial activities. Additionally, silver nanoparticles are under investigation for viricidal effects. Coronavirus has been found to adhere to surfaces and remains there for around $12 \mathrm{~h}$ where the silver-based anti-infective coating can neutralize the virus (Rai et al., 2009; Balagna et al., 2020), studied the anti-infective property of silver by developing the Silver nanocluster-silica composite coated facial mask that exerts a viricidal effect against SARS-CoV-2. This coating can be applied to metallic, glass and ceramic surfaces, so it has vast importance and beneficial application for safety in crowded places like supermarkets, hospitals, and schools to limit the spread of SARS-CoV-2 (Balagna et al., 2020). There are several multifunctional metal nanoparticle/hybrid structures that were explored to limit the range of SARS-CoV-2 through their antiinfective properties as shown in Table $\mathbf{1 .}$

\section{NANOMEDICINE AS A PROMISING APPROACH FOR COVID 19 DIAGNOSTICS}

During the COVID-19 crisis, there was the urgency to develop the diagnostic kits for the early detection of SARS-CoV-2 infection to restrict the movement of the infectious person. Several laboratory-based tests like chest computed tomography, RT-PCR and point of care tests like detection of antibodies against SARS-CoV19 have been developed. This test can be utilized by medical professionals based on the acute and chronic phase of the viral infection. The efficacy of the test depends on various factors like the invasive nature of the infection, and the development of antibodies against antigens presented by the virus in the human body (Li C. et al., 2020). Nanotechnology has played a significant role in the fabrication of the diagnostic tools at various levels such as lateral flow assay (Panda et al., 2020). Surface-enhanced Raman spectroscopy-based detection where metallic nanoparticles have a fundamental role in improving the signal of analytes and its discovery by optical, electrical and immunofluorescent approaches (Kumar et al., 2020; Mujawar et al., 2020). Li C. et al. (2020), have developed a point-of-care, lateral flow immunoassay-based test for the simple and rapid detection of the antibodies (immunoglobulin $\mathrm{M}$ ( $\operatorname{IgM}$ ) and IgG antibodies) against SARS-CoV-2 virus in a human blood sample

\section{REFERENCES}

Al-Qahtani, A. A. (2020). Severe acute respiratory syndrome coronavirus 2 (SARS-CoV-2): emergence, history, basic and clinical aspects. Saudi J. Biol. Sci. 27, 2531-2538. doi: 10.1016/j.sjbs.2020. 04.033

Arun, T., Verma, S. K., Panda, P. K., Joseyphus, R. J., Jha, E., Akbari-Fakhrabadi, A., et al. (2019). Facile synthesized novel hybrid graphene oxide/cobalt ferrite magnetic nanoparticles based surface coating material inhibit bacterial secretion pathway for antibacterial effect. Mater. Sci. Eng. C. Mater. Biol. Appl. 104:109932. doi: 10.1016/j.ms.2019.109932

Balagna, C., Perero, S., Percivalle, E., Nepita, E. V., and Ferraris, M. (2020). Virucidal effect against coronavirus SARS-CoV-2 of a silver in 15 min where the antigen was coated in gold nanoparticles, which further detect the antibodies by the colorimetric reaction. This test can be utilized for the rapid testing of SARS-CoV2 carriers, symptomatic or asymptomatic, in hospitals, clinics, and test laboratories ( $\mathrm{Li} \mathrm{Z}$. et al., 2020). Recently, Li C. et al. (2020) has demonstrated in-depth information about the COVID 19 diagnosis that readers can refer to for a more detailed insight.

\section{CONCLUSION}

Nanomedicine is one of the most important fields of science that has played a substantial role in the development of the novel technology to tackle the problems associated with disease treatment and diagnosis. Several nanocarriers are under investigation to improve the conventional drug delivery systems to effectively target drug releases, low dose, reduced toxicity, improved permeability, and controlled release of the drug. Moreover, nanomedicine has also performed significant parts in creating point-of-care testing to tackle infectious diseases like COVID 19. Cyclodextrin-based Remdesivir formulation is one of the great success of nanomedicine in the treatment of COVID 19 infection. Additionally, plasmonic nanoparticle (Gold, silver, and its hybrid nanostructure) exert anti-infective activity against COVID 19 and has played a vital role in the development of point-of-care diagnostic tests for its detection. Hence, nanomedicine has provided crucial support to manage the COVID 19 pandemic crisis.

\section{AUTHOR CONTRIBUTIONS}

RB: conceived the idea, writing, and data collection. CB: data collection. VC: figure and table. JW: drafting. MS: proofreading and guidelines figure and table. All authors contributed to the article and approved the submitted version.

\section{ACKNOWLEDGMENTS}

RB wants to acknowledge Government of Ireland Postdoctoral fellowship Grant GOIPD/2017/1283. We would also like to acknowledge the Science Foundation Ireland (SFI) and the European Regional Development Fund (Grant Number 13/RC/2073). nanocluster/silica composite sputtered coating. Open Ceramics 1:100006 doi: 10.1016/j.oceram.2020.100006

Bohara, R. A., Throat, N. D., Mulla, N. A., and Pawar, S. H. (2017). Surfacemodified cobalt ferrite nanoparticles for rapid capture, detection, and removal of pathogens: a potential material for water purification. Appl. Biochem. Biotechnol. 182, 598-608. doi: 10.1007/s12010-016-2347-6

Chaturvedi, V. K., Yadav, N., Rai, N. K., Ellah, N. H. A., Bohara, R. A., Rehan, I. F., et al. (2020). Pleurotus sajor-caju-mediated synthesis of silver and gold nanoparticles active against colon cancer cell lines: a new era of herbonanoceutics. Mol. 25:3091. doi: 10.3390/molecules25133091

Chauhan, G., Madou, M. J., Kalra, S., Chopra, V., Ghosh, D., and MartinezChapa, S. O. (2020). Nanotechnology for COVID-19: therapeutics and vaccine research. ACS Nano. 14, 7760-7782. doi: 10.1021/acsnano.0c04006 
Chen, Y.-N., Hsueh, Y.-H., Hsieh, C.-T., Tzou, D.-Y., and Chang, P.-L. (2016). Antiviral activity of graphene-silver nanocomposites against nonenveloped and enveloped viruses. Int. J. Environ. Res. Public Health 13:430. doi: $10.3390 /$ ijerph 13040430

Cho, I. H., Lee, D. G., and Yang, Y. Y. (2014). Composition with sterilizing activity against bacteria, fungus and viruses, application thereof and method for preparation thereof. US20130129805A1.

Ciejka, J., Wolski, K., Nowakowska, M., Pyrc, K., and Szczubiałka, K. (2017). Biopolymeric nano/microspheres for selective and reversible adsorption of coronaviruses. Mater. Sci. Eng. C 76, 735-742. doi: 10.1016/j.msec.2017.03.047

Das, B. K., Verma, S. K., Das, T., Panda, P. K., Parashar, K., Suar, M., et al. (2019). Altered electrical properties with controlled copper doping in $\mathrm{ZnO}$ nanoparticles infers their cytotoxicity in macrophages by ROS induction and apoptosis. Chem. Biol. Interact. 297, 141-154. doi: 10.1016/j.cbi.2018.11.004

de Wit, E., Feldmann, F., Cronin, J., Jordan, R., Okumura, A., Thomas, T., et al. (2020). Prophylactic and therapeutic remdesivir (GS-5734) treatment in the rhesus macaque model of MERS-CoV infection. Proc. Nat.l Acad. Sci. U. S. A. 117, 6771-6776. doi: 10.1073/pnas.1922083117

Dhakal, S., Hiremath, J., Bondra, K., Lakshmanappa, Y. S., Shyu, D.-L., Ouyang, K., et al. (2017). Biodegradable nanoparticle delivery of inactivated swine influenza virus vaccine provides heterologous cell-mediated immune response in pigs. $J$. Control. Release 247, 194-205. doi: 10.1016/j.jconrel.2016.12.039

Du, T., Liang, J., Dong, N., Lu, J., Fu, Y., Fang, L., et al. (2018). Glutathione-Capped Ag2S Nanoclusters Inhibit Coronavirus Proliferation through Blockage of Viral RNA Synthesis and Budding. ACS Appl. Mater. Interfaces 10, 4369-4378. doi: 10.1021 /acsami.7b13811

Hu, C.-M. J., Chang, W.-S., Fang, Z.-S., Chen, Y.-T., Wang, W.-L., Tsai, H.H., et al. (2017). Nanoparticulate vacuolar ATPase blocker exhibits potent host-targeted antiviral activity against feline coronavirus. Sci. Rep. 7:13043. doi: 10.1038/s41598-017-13316-0

Jadhav, K., Deore, S., Dhamecha, D., Rajeshwari, H. R., Jagwani, S., Jalalpure, S., et al. (2018). Phytosynthesis of silver nanoparticles: characterization, biocompatibility studies, and anticancer activity. ACS Biomater. Sci. Eng. 4, 892-899. doi: 10.1021/acsbiomaterials.7b00707

Jones, S. T., Cagno, V., Janeček, M., Ortiz, D., Gasilova, N., Piret, J., et al. (2020). Modified cyclodextrins as broad-spectrum antivirals. Sci. Adv. 6:eaax9318. doi: 10.1126/sciadv.aax9318

Khalaj-Hedayati, A., Chua, C. L. L., Smooker, P., and Lee, K. W. (2020). Nanoparticles in influenza subunit vaccine development: Immunogenicity enhancement. Influenza Other Respir. Viruses 14, 92-101. doi: 10.1111/irv.12697

Kumar, R., Mondal, K., Panda, P. K., Kaushik, A., Abolhassani, R., Ahuja, R., et al. (2020). Core-shell nanostructures: perspectives towards drug delivery applications. J. Mater. Chem. B. 8:8992-9027. doi: 10.1039/D0TB01559H

Kumari, P., Panda, P. K., Jha, E., Kumari, K., Nisha, K., Mallick, M. A., et al. (2017). Mechanistic insight to ROS and Apoptosis regulated cytotoxicity inferred by Green synthesized $\mathrm{CuO}$ nanoparticles from Calotropis gigantea to Embryonic Zebrafish. Sci. Rep. 7:16284. doi: 10.1038/s41598-017-16581-1

Kumari, P., Panda, P. K., Jha, E., Pramanik, N., Nisha, K., Kumari, K., et al. (2018). Molecular insight to in vitro biocompatibility of phytofabricated copper oxide nanoparticles with human embryonic kidney cells. Nanomedicine 13, 2415-2433. doi: 10.2217/nnm-2018-0175

Li, C., Zhao, C., Bao, J., Tang, B., Wang, Y., and Gu, B. (2020). Laboratory diagnosis of coronavirus disease-2019 (COVID-19). Clin. Chim. Acta. 510:35-46. doi: 10.1016/j.cca.2020.06.045

Li, Z., Yi, Y., Luo, X., Xiong, N., Liu, Y., Li, S., et al. (2020). Development and clinical application of a rapid IgM-IgG combined antibody test for SARS-CoV2 infection diagnosis. J. Med. Virol. doi: 10.1002/jmv.25727. [Epub ahead of print].

Liu, Y. C., Kuo, R. L., and Shih, S. R. (2020). COVID-19: The first documented coronavirus pandemic in history. Biomed. J. 43, 328-333. doi: $10.1016 / j . b j .2020 .04 .007$

Lv, X., Wang, P., Bai, R., Cong, Y., Suo, S., Ren, X., et al. (2014). Inhibitory effect of silver nanomaterials on transmissible virus-induced host cell infections. Biomaterials 35, 4195-4203. doi: 10.1016/j.biomaterials.2014.01.054

Mujawar, M. A., Gohel, H., Bhardwaj, S. K., Srinivasan, S., Hickman, N., and Kaushik, A. (2020). Nano-enabled biosensing systems for intelligent healthcare: towards COVID-19 management. Mater. Today Chem. 100306. doi: $10.1016 /$ j.mtchem.2020.100306
Ohno, S., Kohyama, S., Taneichi, M., Moriya, O., Hayashi, H., Oda, H., et al. (2009). Synthetic peptides coupled to the surface of liposomes effectively induce SARS coronavirus-specific cytotoxic T lymphocytes and viral clearance in HLA-A ${ }^{*} 0201$ transgenic mice. Vaccine 27, 3912-3920. doi: 10.1016/j.vaccine.2009.04.001

Panda, P. K., Arul, M. N., Patel, P., Verma, S. K., Luo, W., Rubahn, H. G., et al. (2020). Structure-based drug designing and immunoinformatics approach for SARS-CoV-2. Sci. Adv. 6:eabb8097.

Paul, P., Verma, S., Kumar Panda, P., Jaiswal, S., Sahu, B. R., and Suar, M. (2018). Molecular insight to influential role of Hha-TomB toxinantitoxin system for antibacterial activity of biogenic silver nanoparticles. Artif. Cells Nanomed. Biotechnol. 46, S572-S584. doi: 10.1080/21691401.2018. 1503598

Rai, M., Yadav, A., and Gade, A. (2009). Silver nanoparticles as a new generation of antimicrobials. Biotechnol. Adv. 27, 76-83. doi: 10.1016/j.biotechadv.2008.09.002

Shah, B., Modi, P., and Sagar, S. R. (2020). In silico studies on therapeutic agents for COVID-19: Drug repurposing approach. Life Sci. 252:117652. doi: 10.1016/j.lfs.2020.117652

Sheahan, T. P., Sims, A. C., Leist, S. R., Schäfer, A., Won, J., Brown, A. J. et al. (2020). Comparative therapeutic efficacy of remdesivir and combination lopinavir, ritonavir, and interferon beta against MERS-CoV. Nat. Commun. 11, 222. doi: 10.1038/s41467-019-13940-6

Tai, T.-T., Wu, T.-J., Wu, H.-D., Tsai, Y.-C., Wang, H.-T., Wang, A.M., et al. (2020). A strategy to treat COVID-19 disease with targeted delivery of inhalable liposomal hydroxychloroquine: a non-clinical pharmacokinetic study. bioRxiv [Preprint]. doi: 10.1101/2020.07.09. 196618

Verma, S. K., Jha, E., Panda, P. K., Das, J. K., Thirumurugan, A., Suar, M., et al. Molecular aspects of core-shell intrinsic defect induced enhanced antibacterial activity of $\mathrm{ZnO}$ nanocrystals. (2017a). Nanomedicine 13, 43-68. doi: $10.2217 / \mathrm{nnm}-2017-0237$

Verma, S. K., Jha, E., Panda, P. K., Kumari, P., Pramanik, N., Kumari, S., et al. (2018a). Molecular investigation to RNA and protein based interaction induced in vivo biocompatibility of phytofabricated AuNP with embryonic zebrafish. Artif. Cells Nanomed. Biotechnol. 46, S671-S684. doi: 10.1080/21691401.2018.1505746

Verma, S. K., Jha, E., Panda, P. K., Thirumurugan, A., Patro, S., Parashar, S. K. S., et al. (2018b). Molecular insights to alkaline based bio-fabrication of silver nanoparticles for inverse cytotoxicity and enhanced antibacterial activity. Mater. Sci. Eng. C 92, 807-818. doi: 10.1016/j.msec.2018.07.037

Verma, S. K., Jha, E., Sahoo, B., Panda, P. K., Thirumurugan, A., Parashar, S., et al. (2017b). Mechanistic insight into the rapid one-step facilebiofabrication of antibacterial silver nanoparticlesfrom bacterial release and their biogenicity andconcentration-dependent in vitro cytotoxicity tocolon cells ${ }^{\dagger}$. RSC Adv. 7 , 40034-40045. doi: 10.1039/C7RA05943D

Verma, S. K., Panda, P. K., Jha, E., Suar, M., and Parashar, S. K. S. (2017c). Altered physiochemical properties in industrially synthesized $\mathrm{ZnO}$ nanoparticles regulate oxidative stress; induce in vivo cytotoxicity in embryonic zebrafish by apoptosis. Sci. Rep. 7:13909. doi: 10.1038/s41598-017$14039-\mathrm{y}$

Wu, F., Zhao, S., Yu, B., Chen, Y. M., Wang, W., Song, Z. G., et al. (2020). A new coronavirus associated with human respiratory disease in China. Nature 579, 265-269. doi: 10.1038/s41586-020-2008-3

Zhang, Q., Honko, A., Zhou, J., Gong, H., Downs, S. N., Vasquez, J. H., et al. (2020). Cellular nanosponges inhibit SARS-CoV-2 infectivity. Nano lett. 7, 5570-5574, doi: 10.1021/acs.nanolett.0c02278

Conflict of Interest: The authors declare that the research was conducted in the absence of any commercial or financial relationships that could be construed as a potential conflict of interest.

Copyright $\odot 2020$ Wankar, Chaturvedi, Bohara, Singh and Bohara. This is an openaccess article distributed under the terms of the Creative Commons Attribution License (CC BY). The use, distribution or reproduction in other forums is permitted, provided the original author(s) and the copyright owner(s) are credited and that the original publication in this journal is cited, in accordance with accepted academic practice. No use, distribution or reproduction is permitted which does not comply with these terms. 